\title{
Políticas afirmativas: opinião das pessoas com deficiência acerca da legislação de reserva de vagas no mercado de trabalho
}

\section{Affirmative politics: the people with deficiency's opinions legislación concerning vacancies reservation of in the job market}

\author{
Rosé Colom Toldrá ${ }^{1}$
}

TOLDRÁ, R. C. Políticas afirmativas: opinião das pessoas com deficiência acerca da legislação de reserva de vagas no mercado de trabalho. Rev. Ter. Ocup. Univ. São Paulo, v. 20, n. 2, p. 110117, maio/ago. 2009.

\begin{abstract}
RESUMO: O presente artigo visou refletir acerca da opinião das pessoas com deficiência a respeito da legislação referente à reserva de vagas no mercado de trabalho. Os dados nacionais apontam grandes desigualdades sociais no que se refere à inclusão de pessoas com deficiência no mercado de trabalho, mesmo com as medidas decorrentes da política de cotas que visam à inclusão laboral. $\mathrm{O}$ estudo foi realizado através de entrevista com dez trabalhadores com diferentes tipos de deficiência física e visual inseridas no mercado de trabalho. Como técnica de análise adotou-se o Discurso do Sujeito Coletivo. A legislação foi considerada necessária devido à condição histórica de exclusão vivida pelas pessoas com deficiência, o que levou a falta de oportunidades de capacitação e baixa escolaridade. A legislação contribuiu para a conquista do direito ao trabalho e maior visibilidade social das necessidades das pessoas com deficiência. No entanto, a manutenção das leis deve estar atrelada as mudanças de valores e de atitudes da sociedade e a disponibilização de condições para a inclusão laboral desta população.
\end{abstract}

DESCRITORES: Trabalho/legislação \& jurisprudência. Pessoas com deficiência. Legislação. Políticas públicas. Pesquisa qualitativa.

\footnotetext{
1. Terapeuta Ocupacional; doutora em Sociologia pela Universitat de Barcelona, docente do Curso de Terapia Ocupacional do Departamento de Fisioterapia, Fonoaudiologia e Terapia Ocupacional da Faculdade de Medicina - Universidade de São Paulo.

Endereço para correspondência: rosetoldra@usp.br
} 
TOLDRÁ, R. C. Políticas afirmativas. Rev. Ter. Ocup. Univ. São Paulo, v. 20, n. 2, p. 110-117, maio/ago. 2009.

\section{INTRODUÇÃO}

$P$ ara estudar e compreender as práticas relativas às pessoas com deficiência é importante considerar que, só a partir da Constituição de 1988, a sociedade brasileira construiu uma política que acolheu a diversidade social e aprovou leis que reconheceram os direitos das pessoas com deficiência. Apesar da Carta das Nações Unidas e da Declaração Universal dos Direitos Humanos afirmarem sobre a dignidade e igualdade de direitos a todas as pessoas e a Convenção $\mathrm{n}^{\circ} 111$ da Organização Internacional do Trabalho em 1958 tratar da discriminação em amplo espectro em relação às pessoas com deficiência, somente após algumas décadas o Brasil começa a mudar suas ações e legislações de caráter assistencial para adotar finalmente uma perspectiva de aprimoramento das legislações e políticas públicas no sentido da inclusão das pessoas com deficiência a partir da concepção do direito e da cidadania.

A promoção da inclusão esta apoiada na igualdade, na eqüidade e na disponibilização de condições para que ocorra essa igualdade, o que pressupõe mudanças na sociedade para que todos possam desfrutar de melhores condições de vida (BRASIL, 2007). Trata-se, portanto, de um longo processo que envolve transformações de valores e atitudes sociais e a realização de mudanças objetivas para que as necessidades de todos possam ser atendidas.

O sistema produtivo é considerado fundamental no processo de construção de uma sociedade mais justa e igualitária e é a partir da relação sócio-político-econômica que se cria o sistema de valoração a partir do qual as pessoas são socialmente avaliadas (NAMBU, 2003). Como o trabalho se dá no contexto de relações sociais de produção este determina o desenvolvimento do indivíduo, a construção da identidade pessoal e social, assim como auto-estima e consciência de dignidade (ARANHA, 2003; NAMBU, 2003; SAINT-JEAN, 2003).

O estudo sobre o trabalho é um tema histórico na Terapia Ocupacional e a discussão sobre a inclusão no mercado de trabalho de pessoas com deficiência é um tema recente, que implica questões diversas. Refletir sobre o trabalho envolve a compreensão do processo de globalização, as transformações atuais do mundo do trabalho, as mudanças das organizações, as exigências do perfil dos trabalhadores, a instabilidade do trabalhador e as relações cada vez mais precárias existentes no mundo do trabalho contemporâneo(LANCMAN, 2004). Condições estas que influenciam de alguma maneira o contexto de trabalho das pessoas com deficiência.

Os estudos sobre a inclusão de pessoas com deficiência no mercado de trabalho mostram dados preocupantes. O Censo do IBGE de 2000 revela que $14,5 \%$ da população brasileira apresentam algum tipo de deficiência, perfazendo um total aproximado de 24,6 milhões de brasileiros. Esse número é mais de dez vezes superior aos dados do Censo de 1991, que apontava 1,5\% da população com algum tipo de deficiência (NÉRI et al., 2003). Tal contraste de dados em tão curto período de tempo pode demonstrar um melhor registro e superação de dificuldades conceituais, o que trouxe como conseqüência uma aproximação com a realidade nacional e possibilidades de estabelecer correlações com os dados internacionais (BRASIL, 2009).

Até a última década do século XX, não existiam no país dados oficiais sobre as pessoas com deficiência. Tomava-se como referência a estimativa da OMS, a qual previa que $10 \%$ da população, em tempos de paz, possuí algum tipo de deficiência. Somente com a lei $n^{\circ} 7853 / 89$ tornou-se obrigatório a inclusão de informações específicas sobre a população com deficiência nos censos nacionais (BRASIL, 2009).

No que se refere ao trabalho, segundo Pastore (2000) o país possui uma das menores taxas de participação de pessoas com deficiência. A Organização Internacional do Trabalho - OIT (2004) indica que o desemprego de pessoas com deficiência com idade para trabalhar no Brasil é muito maior do que para os demais indivíduos economicamente ativos. Segundo estimativas disponíveis, 9 milhões de pessoas com deficiência estão em idade de trabalhar no Brasil. Destes, os que trabalham no mercado formal somam cerca de 2\% (PASTORE, 2000).

Deste modo, os dados acima apontam as grandes desigualdades sociais existentes no país no que se refere à inclusão das pessoas com deficiência no mercado de trabalho, apesar de nos últimos anos ganhar maior visibilidade no território nacional as ações que buscam a inclusão no mercado de trabalho, devido à política de cotas. A reserva legal de cargos também conhecida como Lei de Cotas $n^{\circ} 8.213 / 91$ surgiu como um facilitador para inserção de pessoas com deficiência no setor privado e dispõe sobre a quantidade de empregados nas empresas. A legislação estabeleceu que as empresas que possuem 100 ou mais empregados tem a obrigatoriedade de preencher de $2 \%$ a $5 \%$ dos seus cargos com beneficiários reabilitados ou com pessoas com deficiência, ou seja, empresa com até 200 empregados, deverá preencher $2 \%$ de suas vagas; de 201 a 500 trabalhadores com 3\%; de 501 a 1.000 com 4\%; e finalmente, de 1.000 em diante, $5 \%$. Para o setor público a Lei $n^{\circ} 8.112 / 90$, artigo $5^{\circ} \S 2^{\circ}$ define que até $20 \%$ dos cargos públicos em concursos sejam destinados às pessoas com deficiência. 
TOLDRÁ, R. C. Políticas afirmativas. Rev. Ter. Ocup. Univ. São Paulo, v. 20, n. 2, p. 110-117, maio/ago. 2009.

A legislação brasileira apesar de ser considerada uma das mais avançadas no que se refere à inclusão social desta população, somente em 1999 com o decreto de $n^{\circ}$ 3298 estabeleceu a fiscalização pelos órgãos responsáveis. Isto tornou a discussão sobre o trabalho das pessoas com deficiência mais conhecida, promoveu maior conscientização e mostrou para a sociedade a necessidade de capacitação destas pessoas (MENDONÇA, 2007).

As legislações existentes buscam a implementação efetiva do princípio de igualdade e, por isso, se caracterizam como uma ação afirmativa, pois visam reduzir as desigualdades sociais, presentes neste grupo populacional. No entanto, a existência de leis que dispõem sobre a inclusão laboral das pessoas com deficiência, não a asseguram. Assim, com esta finalidade foi sancionada a Instrução Normativa ${ }^{\circ}$ 20/01 que descreve os procedimentos a serem observados pela Fiscalização do Trabalho no cumprimento da legislação relativa ao trabalho das pessoas com deficiência entre outras informações relativas à inserção laboral.

Considerando o exposto acima o presente artigo visou contribuir com esta temática a partir da reflexão acerca da opinião das pessoas com deficiência a respeito da legislação de reserva de vagas no mercado de trabalho e de sua aplicação, como parte de um estudo mais amplo a respeito da experiência de trabalho de pessoas com deficiência.

\section{METODOLOGIA}

O presente trabalho ocorreu em 2008, no município de Campinas e envolveu dez trabalhadores com diferentes tipos de deficiência física e visual, inseridos no mercado de trabalho em diferentes empresas e ramos de atividade profissional. Os mesmos foram localizados a partir das indicações dadas por instituições de referência do município tais como: Sub Delegacia Regional do Trabalho de Campinas, Centro de Vida Independente de Campinas - CVI, SORRI-Campinas e Instituto Campineiro do Cego Trabalhador. Os tipos de deficiência selecionados foram devido à necessidade de se garantir a capacidade de entendimento, de expressão e de compreensão, dada a natureza do estudo.

O estudo caracterizado no campo da pesquisa qualitativa foi realizado por meio de entrevista utilizando como recurso uma questão aberta para coleta dos dados. A questão formulada foi: "Comente qual a sua opinião sobre a legislação referente à inclusão no mercado de trabalho para as pessoas com deficiência". A técnica escolhida para a análise das informações foi o Discurso do Sujeito Coletivo. O DSC como estratégia discursiva, busca deixar mais clara uma dada representação social (LEFRÈVE, LEFRÈVE,
2003). Assim, como pesquisa no campo da representação social buscou-se estudar o imaginário social a respeito da legislação referente à reserva de vagas no mercado de trabalho para as pessoas com deficiência, através do discurso da realidade, a partir da experiência do sujeito.

Para a sua realização foram adotadas as seguintes etapas no estudo: transcrição dos discursos em estado bruto que foram submetidos a um trabalho analítico inicial de decomposição, para extrair as idéias centrais e as expressões chaves presentes em cada dos discursos individuais, em seguida buscou-se reconstruir com os diferentes depoimentos uma representação social sobre o fenômeno estudado através de um discurso-síntese. $\mathrm{O}$ discurso-síntese foi redigido na $1^{\mathrm{a}}$ pessoa do singular, composto pelas expressões chaves que contém a mesma idéia central.

A pesquisa foi aprovada pelo Conselho de Ensino e Pesquisa da PUC-Campinas e as entrevistas foram realizadas após apresentação do Termo de Consentimento Livre e Esclarecido, nos locais indicados pelas pessoas, com duração média de trinta e cinco minutos.

\section{RESULTADOS E DISCUSSÃO}

A seguir são apresentados os dados que permitiram estabelecer um perfil dos trabalhadores com deficiência, participantes do estudo. Do total de 10 entrevistados, 3 trabalhadores eram do sexo feminino e 7 do sexo masculino, sendo 8 solteiros e 2 casados, com idade que variou de 21 a 36 anos, com média de idade de 29 anos. Os diagnósticos compreenderam: lesão medular (2), amiotrofia espinhal (1), distrofia muscular progressiva (1), amputação de membros superiores (1), artrogripose (2), paralisia cerebral (1) e deficiência visual (2), destes 6 possuíam deficiência congênita e 4 deficiênncia adquirida de 10 a 12 anos.

Observou-se um predomínio de informantes do sexo masculino (7) em relação ao sexo feminino (3), sendo a maior parte pessoas solteiras (8). Quanto ao grau de escolaridade variou entre o nível médio (4) e o nível superior (6). A formação profissional mostrou-se diversificada, no entanto, um maior número de pessoas no campo da informática (4) e o restante jornalista (1), enfermeiro (1), técnico mecânico (1), professor especial (1), economista (1),e um trabalhador sem formação específica . O tempo de trabalho na empresa variou de 2 meses a 9 anos, sendo que 7 pessoas já tiveram empregos anteriores.

Os dados apresentados acerca da percepção sobre a legislação de reserva de vagas para a inclusão no mercado de trabalho de pessoas com deficiência serão apresentados sob a forma de DSC. A questão realizada a respeito da opinião acerca da legislação para a inclusão no mercado de trabalho 
TOLDRÁ, R. C. Políticas afirmativas. Rev. Ter. Ocup. Univ. São Paulo, v. 20, n. 2, p. 110-117, maio/ago. 2009.

de pessoas com deficiência foram selecionados 3 discursos, considerados mais significativos.

Os discursos serão apresentados na forma de narrativa em itálico, para indicar uma fala ou um depoimento coletivo, conforme indica o método. As idéias centrais encontradas nos depoimentos foram:

a- Se não houvesse as leis as empresas não contratariam pessoas com deficiência;

b- A lei de cotas permite diminuir os preconceitos e mostrar as capacidades das pessoas com deficiência;

c- As pessoas com deficiência não tem capacitação, trabalham em ocupações mais simples e de menor remuneração.

Dsc A - Se não houvesse as leis as empresas não contratariam pessoas com deficiência.

A legislação é um mal necessário, pela nossa história, nossa realidade. Foi algo importante por que se não tivesse a lei as empresas... dificilmente as empresas iriam abrir as portas. As empresas já tinham um ou outro deficiente, mas não é tanto igual tem hoje. Olha ... é uma faca de dois gumes, por um lado, é complicado existir a lei, por outro lado, se for pra ter emprego, é interessante, por que se não tiver as cotas eu não sei se as empresas contratariam. $O$ país tem um vício que tudo tem que ser a fórceps, assim as políticas afirmativas são essenciais. O brasileiro só aprende quando leva umas esporadas, as pessoas só fazem as coisas pressionadas.

Primeiro deve-se forçar a inclusão das pessoas com deficiência, para depois falar em pé de igualdade. Quando estivermos incluídos voltamos a discutir. Todo mundo tem direitos iguais, mas não se podem cobrar direitos iguais a partir da situação de desigualdade, da condição de excluídos. Vejo a lei como algo temporário, assim como outras ações afirmativas, devem durar por um tempo, porque senão se perpetua uma situação de diferenciação, de pessoas que precisam ser tuteladas, para conseguir sua cidadania.

Verifica-se pelo discurso que os princípios básicos de cidadania, muitas vezes são violados, levando a discriminação e exclusão das pessoas com deficiência no mundo do trabalho. Os informantes apresentam uma consciência crítica da realidade e defendem o direito de participação social como cidadãos. De acordo com Ferronatto; Wagner; Falkenbach (2008) os princípios de exclusão, decorrentes da história de discriminação, preconceitos e falta de informação, são reelaborados pelas representações sociais e incorporados ao imaginário social como "atributos naturais" de um grupo, gerando as formas de relações sociais, conduzindo as práticas e o acesso às oportunidades de emprego.

Embora se verifique um aumento dos movimentos sociais favorecendo o processo de inclusão das pessoas com deficiência, juntamente com as leis, ainda existe muita resistência das empresas para a contratação das mesmas. Assim a legislação contribuiu para a conquista do direito ao trabalho e maior visibilidade social das necessidades das pessoas com deficiência.

Do mesmo modo a Classificação Internacional de Funcionalidade, Incapacidade e Saúde - CIF (OMS, 2003) contribui de forma positiva na mudança de visão da pessoa com deficiência, na medida em que valoriza a capacidade do individuo no seu ambiente de vida, incluindo o trabalho, ao invés da incapacidade e da impotência como tradicionalmente ocorria. Para a classificação os processos de incapacidade e funcionalidade são considerados resultantes da interação de uma condição de saúde com os fatores do contexto, que podem ser facilitadores ou criarem barreiras.

No entanto, conforme o discurso a legislação é considerada como provisória e sua manutenção esta relacionada às reais possibilidades de inclusão. Assim, a manutenção das leis deve estar atrelada as mudanças de valores, atitudes e conceitos da sociedade, para que ocorra sua efetivação. Ademais, o trabalho é um lugar privilegiado para difundir a cultura inclusiva, já que ocupa um lugar de destaque na vida dos indivíduos

Dsc B - Lei de cotas permite diminuir os preconceitos e mostrar as capacidades das pessoas com deficiência.

No mercado de trabalho ainda as barreiras são imensas, então eu vejo que as cotas ajudam a quebrar preconceitos, engolir as pessoas com deficiência, para então poder mostrar o potencial, traz a discussão à tona. Um trabalho de conscientização pelo governo seria um caminho, dada à falta de conhecimento, para mostrar as capacidades, as possibilidades e dificuldades das pessoas, também uma forma de diminuir o preconceito.

A lei de cotas trouxe uma abertura de horizontes..... Temos que aproveitar pra que daqui a 10 anos a pessoa contrate a gente como uma pessoa normal, capacitada. Agora vamos conseguir mostrar para as pessoas que somos capazes, poder ingressar na sociedade, né? O nosso papel é mostrar que somos capazes. A empresa é obrigada a pegar, mas não acredita nas pessoas.

Quando o empresário é obrigado a contratar o deficiente, não é porque ele quer, porque ele sente aquela pessoa como um cara normal. As empresas foram pegas 
TOLDRÁ, R. C. Políticas afirmativas. Rev. Ter. Ocup. Univ. São Paulo, v. 20, n. 2, p. 110-117, maio/ago. 2009.

de calças curtas. Elas sabiam que existiam leis, mas nunca se preocuparam com isso e quando a fiscalização bate na porta com multa ai estão criando cargos.

Eu acho interessante o que esta sendo feito por parte do governo através da fiscalização pelo Ministério do Trabalho, pois não adianta ter a lei. É necessário efetivar a lei, o problema é fazer cumprir, pois o que diz a legislação ainda não acontece.

No discurso se reconhece o papel social da política de reserva de vagas como necessária tendo em vista o histórico de discriminação. Esta colabora com o desenvolvimento de uma sociedade mais justa e solidária na medida em que se contrapõe a discriminação e ao preconceito, que sempre excluíram as pessoas com deficiência do convívio social. No entanto, depende das empresas e da conscientização da sociedade para o cumprimento do que propõe a legislação.

Isto supõe a valorização das práticas que envolvem a responsabilidade social das empresas, ou seja, estas devem encarar a inclusão de pessoas com deficiência no trabalho como uma oportunidade de desenvolvimento de relações humanas positivas, que podem ter repercussões em todos os aspectos da empresa. Desta forma a empresa ao opor-se ao preconceito e reconhecer a igualdade entre as pessoas, em consonância com Constituição Brasileira de 1988, o Programa de Ação Mundial para as Pessoas com Deficiências da ONU entre outros documentos nacionais e internacionais difundem uma postura ética, da qual deve fazer parte o mundo empresarial.

Vários mecanismos legais garantem o acesso da pessoa com deficiência ao mercado de trabalho. No entanto, o desconhecimento das capacidades das pessoas com deficiência é apontado como um dos aspectos mais significativos para o não cumprimento da lei (BRASIL, 2007). Assim, um primeiro passo seria conhecer a realidade, para depois poder divulgar e socializar as informações. A disseminação da informação é considerada uma ferramenta importante no sentido de oportunizar as pessoas com deficiência a exercer sua cidadania (NAMBU, 2003), para que o cidadão e a sociedade organizada possam transformar informações em participação cidadã (SILVA, 2007). Isto reforça a necessidade de ampliação da informação sobre as pessoas com deficiência e integração dos serviços de saúde e instituições voltados à atenção as pessoas com deficiência, que se mostraram desarticulados conforme aponta Toldrá e Sá (2008) e Rodrigues et al. (2009) em estudo realizado no município de Campinas e em São Carlos respectivamente.

É necessário tornar a inclusão eficaz e garantida, pois não adianta ter legislação vigente de qualidade, se na prática não há a eficiência de realizar o que está descrito na lei e fazer valer os direitos daqueles, que por algum motivo, foram excluídos da sociedade em que vivem (FÁVERO, 2004).

Apesar de lentas as possibilidades de acesso ao trabalho das pessoas com deficiência começam a surtir efeito por meio da fiscalização e punições às empresas que não vinham cumprindo com a lei (FERRONATTO et al., 2008). A legislação, principalmente a lei de cotas, constitui um primeiro passo, mas não necessariamente, sensibiliza e garante efetivas contratações para o mercado de trabalho, isto depende de uma ação conjunta do Estado e da sociedade civil.

Apesar da legislação vigente estar sendo atualizada e progredindo lentamente no sentido da manutenção dos direitos das pessoas com deficiência, ainda, o desconhecimento sobre esses direitos por parte das empresas e da sociedade em geral cria barreiras para a inclusão laboral das pessoas com deficiência.

Dsc C - As pessoas com deficiência não tem capacitação, trabalham em ocupações mais simples e de menor remuneração.

As pessoas com deficiência tem se concentrado ainda em ocupações mais simples. Oferecem emprego para o deficiente com salário muito inferior pela cultura. Porque o deficiente não tem acesso à educação. Os deficientes geralmente se dedicam aos serviços gerais, almoxarifado, acredita-se que o deficiente não tem condições de fazer serviços mais qualificados. No geral, pensam que a pessoa com deficiência não é qualificada e contratam com salários baixos. Não é só bordado, não é só basquete, a pessoa com deficiência pode muito mais. Estudos têm demonstrado que as pessoas com deficiência tem se concentrado em ocupações mais simples, ocupações de menor remuneração. É uma realidade que a gente também tem que tentar mudar, as pessoas com deficiência podem entrar na área de tecnologia, na área de gerencia, na área administrativa e não precisam estar sempre trabalhando na produção, podem também ter postos mais qualificados nas empresas.

O que falta hoje em dia, na verdade, é capacitação, o que adianta ter essa lei de cotas, sendo que a pessoa com deficienncia não tem capacitação. As empresas exigem o segundo grau completo e geralmente os deficientes não tem, não estão preparados para o mercado de trabalho, não tem um curso de inglês, não tem um curso básico de informática para está trabalhando em outro setor que não seja a produção

Têm locais que você vai fazer entrevista e falam: a 
TOLDRÁ, R. C. Políticas afirmativas. Rev. Ter. Ocup. Univ. São Paulo, v. 20, n. 2, p. 110-117, maio/ago. 2009.

vaga é essa, então parece que é assim, você é deficiente a gente abriu essa vaga, a gente criou, porque eu já escutei isso de boca de RH. Então, parece que é ali que você vai ficar e você vai estagnar. Quero ser um funcionário como qualquer um e executar a função que seja determinado para mim. Não adianta entrar numa empresa para executar determinada coisa, e o cara me colocar pra ficar amassando papel. Eu não quero ser uma pedra no sapato.

O discurso representa a realidade da maioria da população com deficiência, apesar dos participantes do estudo apresentarem um nível de escolaridade superior e um conjunto de ocupações que diferem de grande parte do coletivo.

Corresponde ao discurso os dados de pesquisa realizada em instituições específicas para pessoas com deficiência na cidade de Campinas que desenvolviam propostas voltadas a capacitação e inserção no mercado de trabalho de pessoas com deficiência. Esta revelou que as legislações possibilitaram mudanças e um maior número de contratações, no entanto, as dificuldades residiam quanto à exigência de escolaridade das empresas, denotando o desconhecimento dos empresários quanto à realidade desta população. Verificou-se, ainda, pouca inserção de pessoas com deficiência nas propostas de capacitação oferecidas pela secretaria municipal responsável por esta área, o que assinala uma falta de integração entre as políticas públicas municipais (TOLDRÁ; SÁ, 2008).

Outro estudo desenvolvido em instituições que prestam assistência a esta população no município de São Carlos também confirma o depoimento. O mesmo mostrou que os limites para o ingresso no mercado de trabalho se referem à baixa escolaridade e a falta de recurso e estrutura para capacitação e, no tocante à ocupação as pessoas empregadas desempenhavam funções principalmente na área de produção (RODRIGUES et al, 2009).

Assim, constata-se que tanto as instituições de assistência, as empresas e os órgãos públicos necessitam rever suas ações e caminhar na direção das políticas de inclusão social de forma articulada, para romper com o ciclo de discriminação vivido por este coletivo.

No entanto, mesmo considerando-se a pertinência das leis, isso não garante efeitos imediatos. A viabilidade das mesmas dependerá de uma rede complexa que exigirá de todos os envolvidos direta ou indiretamente uma (re) posição, uma (re)visão das referências em que se baseiam os conceitos e os preconceitos da sociedade, os quais devem ter repercussão no âmbito político, econômico e institucional (QUINTÃO, 2005).

Uma iniciativa que pode ser ressaltada foi a elaboração do Repertório de Recomendações Práticas da OIT por meio do documento "Gestão de questões relativas à deficiência no local de trabalho" que teve como objetivo orientar os empregadores quanto a adoção de estratégias positivas de gestão junto as pessoas com deficiência em situações de trabalho, buscando medidas que visem o estabelecimento de igualdade de oportunidades, tendo em vista os obstáculos apontados acima.

Autores (FERRONATTO et al., 2008) ponderam que mesmo que as pessoas com deficiência estivessem preparadas para o mercado de trabalho, dificuldades decorrentes do estigma e do desconhecimento sobre as capacidades e potencialidades destas pessoas ainda poderiam impossibilitar uma adequada inserção laboral.

Assim, apesar de alguns passos terem sido dados no sentido de possibilitar a inclusão no mercado de trabalho das pessoas com deficiência, o processo histórico da relação de exclusão das sociedades para com as mesmas, ainda, dificulta o desenvolvimento de uma identidade positiva destas pessoas.

No entanto, este processo desfavorece a contribuição que as pessoas com deficiência podem oferecer para a construção da sociedade, mas também desfavorece a humanização da própria sociedade, na medida em que a inclusão de pessoas com deficiência é um significativo aprendizado para a promoção e respeito à diversidade no ambiente de trabalho.

Por fim, a empresa responsável no cumprimento dos princípios voltados aos valores que defendem a cidadania e os direitos humanos, por meio da promoção da diversidade e da eliminação da discriminação estará contribuindo para a criação de mudanças positivas nas relações humanas no mundo do trabalho.

\section{CONSIDERAÇÕES FINAIS}

Apesar do reconhecimento dos benefícios decorrentes das iniciativas de legislações e políticas públicas que promovem à inclusão de pessoas com deficiência no mercado de trabalho na perspectiva do direito e da cidadania, ainda, verifica-se conforme o estudo dificuldades devido ao desconhecimento da legislação, a falta de aplicação e de conscientização das empresas quanto à necessária modificação de atitudes e valores em relação às pessoas com deficiência, para que ocorra sua contratação.

Os depoimentos indicam que a legislação é considerada necessária devido ao histórico de discriminação vivido por este coletivo, no entanto, a sua manutenção deve estar vinculada ao grau de conscientização da sociedade como 
um todo e a disponibilização de condições objetivas para a inclusão laboral desta população.

Para nos direcionarmos na perspectiva da sociedade inclusiva se faz necessário um esforço conjunto de todos os envolvidos - políticas públicas, de empresas e a sociedade em geral, no sentido de eliminar os preconceitos, discriminações, barreiras sociais, culturais e pessoais em todos os âmbitos, incluindo o trabalho.

TOLDRÁ, R. C. Affirmative politics: the people with deficiency’s opinions legislación concerning vacancies reservation of in the job market. Rev. Ter. Ocup. Univ. São Paulo, v. 20, n. 2, p. 110 117, maio/ago. 2009.

\begin{abstract}
S: The present article seeks to contemplate concerning the people with deficiency's opinions regarding the legislation of vacancies reservation in the job market. The national data point that great social inequalities refering to the people with deficiency's inclusion in the job market, even with the current politics measures of quotas that seek to laboral inclusion. The study was accomplished through interview with ten workers handling different types of physical and visual deficiency inserted in the job market. As data analysis technique was adopted the Collective Subject's Speech methodology. The legislation was considered necessary due to the historical condition of exclusion experienced by people with deficiency, considering the lack of training opportunities and low educational level. The legislation contributed to the conquest of rights to the workfield and larger social visibility of the people with deficiency's needs. However, the maintenance of the laws should be harnessed the changes of values and attitudes of the society and the avaiability of conditions for laboral inclusion of this population.
\end{abstract}

KEY WORDS: Work/legislation \& jurisprudence. Inclusion/exclusion at work. Legislation. Public policies. Qualitative research. Disabled persons.

\title{
REFERÊNCIAS
}

ARANHA, M. S. F. Trabalho e emprego: instrumento da construção da identidade pessoal e social. São Paulo: SORRIBRASIL; CORDE, 2003. Série Coleção Estudos e Pesquisas na Área da Deficiência; v.9. Disponível em: http://www.presidencia. gov.br/sedh. Acesso em: 23 maio 2007.

BRASIL, Ministério do Trabalho e Emprego. Instrução normativa $n^{\circ} 20$ de 26 de Janeiro de 2001. Disponível em: http://www.mte. gov.br/legislacao/instrucoes_normativas/2001/in_20010126_20. asp. Acesso em:16 de Jun. 2008.

BRASIL, Ministério do Trabalho e Emprego. A inclusão das pessoas com deficiência no mercado de trabalho. Brasília: MTE, SIT, DEFIT, 2007.

BRASIL, Ministério da Saúde. Secretaria de Atenção à Saúde. Política Nacional de Saúde da Pessoa Portadora de Deficiência. Brasília, 2009.

FÁVERO, E.A.G. Direitos das pessoas com deficiência: garantia de igualdade na diversidade. Rio de Janeiro: WVA Editora, 2004.
FERRONATTO, B. C.; WAGNER; L. C.; FALKENBACH, A. P. Inclusão laboral da pessoa portadora de deficiência. Rev. Digital, Buenos Aires, v. 12, n. 117. Disponível em: <http://www. efdeportes.com>. Acesso em: 12 fev. 2008.

INSTITUTO BRASILEIRO DE GEOGRAFIA E ESTATÍSITICA (IBGE). Censo demográfico de 2000. Características gerais da população. Rio de Janeiro, 2002. Disponível em: <http://www. ibge.gov.br. Acesso em: 23 abr 2007.

LANCMAN, S. Construção de novas teorias e práticas em terapia ocupacional, saúde e trabalho. In: LANCMAN, S (Org). Saúde, trabalho e terapia ocupacional. São Paulo: Roca, 2004.

LEFÉVRE, F.; LEFÉVRE, A. M. C. O discurso do sujeito coletivo. Um novo enfoque em pesquisa qualitativa (Desdobramentos). Caxias do Sul, RS: EDUCS, 2003.

MENDONÇA, R. C. T. Breves comentários sobre os dispositivos legais que subsidiam a politica de inclusão das pessoas com deficiência no mercado de trabalho. 2007. Disponível em: $<$ http//:saci.org.br/index.php?modulo=akemi\&parametro $=19683$ 
TOLDRÁ, R. C. Políticas afirmativas. Rev. Ter. Ocup. Univ. São Paulo, v. 20, n. 2, p. 110-117, maio/ago. 2009.

>. Acesso em: 22 jun 2009.

NAMBU, T. S. Construindo um mercado inclusivo: guia prático para profissionais de recursos humanos. São Paulo: SORRIBRASIL; Brasília: CORDE, 2003

NERI, M. et al. Retratos da deficiência no Brasil. - PPD. Rio de Janeiro: FVC/IBRE, CPS, 2003.

ORGANIZAÇÃO INTERNCIONAL DO TRABALHO. Secretaria Internacional do Trabalho - Brasil. Gestão das questões relativas à deficiência no local de trabalho. Brasília: OIT, 2004. Disponível em: <http://www.oit.org/brasília>. Acesso em: 23 abril 2007.

ORGANIZAÇÃO PANAMERICANA DE SAÚDE E ORGANIZAÇÃO MUNDIAL DE SAÚDE. Classificação Internacional de Funcionalidade, Incapacidade e Saúde. São Paulo: Editora da Universidade de São Paulo, 2003.

PASTORE, J. Oportunidades de trabalho para pessoas com deficiência. São Paulo: Ltr, 2000.
RODRIGUES, D. S.; SIMONELLI, A.P.; SOARES, L. B. T.; CAMAROTTO, J.A. Caracterização das pessoas com deficiência em idade economicamente ativa e mapeamento das instituições de assistência atuantes no Município de São Carlos. Cad. Ter.Ocup. UFSCar, São Carlos, v. 17, n. 2, p. 107-118, jul-dez., 2009.

QUINTÃO, D.T.R. Algumas reflexões sobre a pessoa portadora de deficiência e sua relação com o social. Psicol. Soc., v. 17, n. 1, p. 75-80, Abr. 2005. Disponível em: <http://www.scielo.com.br $>$. Acesso em: 09 maio 2006.

RIBAS, J. B. Pessoas com deficiência e emprego formal: As dificuldades que as empresas têm encontrado para contratar, 2004. Disponível em: <http://www.universia.com.br>. Acesso em: 14 maio 2008.

SAINT-JEAN, M. Organização do trabalho e saúde mental. Rev. Ter. Ocup. Univ. São Paulo, v.14, n. 3, p.48-51, jan./abr/ 2003.

TOLDRÁ, R. C.; SÁ, M. J. C. N. A profissionalização de pessoas com deficiência em Campinas: fragilidades e perspectivas. Rev. Ter. Ocup. Univ. São Paulo, v. 19 n. 1 p. 48-55, jan/abr. 2008. 